\title{
Communicating Grassroots Innovation and Community Action for Sustainable Development in India for Women - A Researcch on Shyamala Vaani Community Radio, Madurai
}

\section{K.Abirami}

\begin{abstract}
Sustainability in environment is the key to achieve the goals for development. In the media, we have a lot of environmental issues, by regarding this the policy makers and the wider community people have taken action towards the green intiatives in the village people through community radio. Community Radio mainly represent for the people with a beautiful tagline like "By the People, of the people and for the people" leads to represent the different social, economic and cultural context. Women Empowerment and their magnitude development are major affair in the process of evolution. In India, above 850 million people are denied from a vast range of understanding information and knowledge and some of the rural people are isolated without any kind of impact. Traditional Media, New media and Development communication which would develop our livelihood pattern and also the way of communicating with each other. For the rural, poor people within certain communities "Community Radio" has been proved as the most effective medium of capability and comprehensive to provide impartial content and useful programme among the certain community mankind. The aim of this research is to analyze the benefaction of community radio for women empowerment in SHYAMALAVAANI COMMUNITY RADIO. From this detailed analysis, community radio programmes has created fully participation among Community audience and also equal circulation of ideas among this particular community. This is expected to reveal some attention to all the people for the programmes and effectiveness among women to get authority and get more confident in sway your life and hold their rights.
\end{abstract}

Key Words: Environmental Communication, Community Radio, Sustainable Development in India

\section{INTRODUCTION}

In India, women have chosen to use to replace the medium to get over from the gender objectivity and sustainable growth. Community media and other communication technologies are legalizing women to discuss and put forth about their rights and certify them through knowledge about social, political economic and environmental policies. Community radio acts as a conveyance for the local community, NGOs and citizens to work for the development in the particular community people especially women. Now a

Revised Manuscript Received on December 24, 2019

K. Abirami, Department of Visual Communication, Kalasalingam Academy of Research and Education, Krishnankoil, Tamil Nadu, India. Email: abikathiresh@gmail.com. days, community radio stations offered a variety of programmes to encourage their listeners to participate actively to share their experience too. Community radio moved towards the local area people who are especially immigrants and the poor people who didn't get their media background .The special feature in the community radio is the people who will produce their own shows and participate by voluntarily at any time for their own benefit. The essential role for community radio is to energize women and also to create awareness, develops their skills, create education background and also to demand about how to live in the society? .Many researchers have proved that the Community Radio is the only gadget to metamorphose the women mortal. "Women Empowerment is literally meant by nourishing them to tackle their family, their conventional forces ,societal forces and the male dominance in working place within the particular society .This collision safeguard their full participation in every characteristic of social and national development. With this awareness from the CR they gain self-confidence and strength to challenge gender inequalities at the household, community, national , regional, and international levels .

Achieving Women's empowerment is not an easy task by using the role of community radio. Role of community radio in empowering women It is not easy to achieve women's empowerment. In contemporary world, Eradicating and creating awareness among women is one of the most stereotypical propaganda through electronic media and New media and also social media. This gives the shapes and opinions among women in this world. Especially, Visual Media is more actively participating to get over from this suppress between gender. Feminists are also actively taking part to give over the very popular methods like training programme for women which is full of entrepreneurship, self help without the dependence of others, social activity etc.

In most of the media especially like advertising women are portrayed as a decorative role in spite of traditional role. The women who showed in the media are not in a real form. with equal to this, in the recent days women can be given as a more decision making process by holding the media through this they can earn their output. These are all the process which has been actively involved in the community

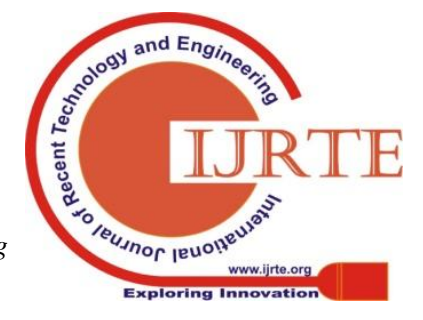


action for women empowerment.

\section{LITERATURE REVIEW}

\section{A. The Role of Community Radio in Livelihood} Improvement

From the study of Community Radio in livelihood improvement proves that the Simli Radio has toiled to provide solutions to their nearby community problems and also they give the solution which has been from their modifications in culture, development of their rural city to village, local community children's education, ameliorate hygiene conditions, enhance their poor sanitary issues to particular local community people. These are all the actions which has been taken from Simli Community Radio to particular community people. This medium has been an proper medium to get the bond between responsible conveyor and honorable receivers.

This community station also promotes marketing strategies for the particular community people by using the radio stations. This will enhance their agriculture business tool to improve their income from agriculture through community radio also. This radio station also endorse that they check out their regular feedback from listeners either it is positive or negative. And they also give some response to the listeners taste and if they suggest any of the programmes, they has been changed according to the listeners preference. And they always avoid politics and religion either from the community or from the worldwide.

\section{B. The Role of Community Radio in Rural Development.}

The role of community radio in rural development was written by Saad Ullah Khan Through his research he says that after independence we achieved marvelous amount of success in many media especially social media but till now community radio becomes the world wide developing medium especially for women and agriculture. Now the growth rate has raised from 3\% to $9 \% \mathrm{~T}$.

Most of the people living in villages but still they are in backward conditions. Now they are facing the problems like scarcity, deficiency, lack of education, lack of hygiene, unwaged etc. For the rural development government has been spending amount to change back like urban remote cities but they did not get an aware of these because of the lack of communication between the governments formulate policies and standard mass people and also they ignored these kind of policies. From the grass root level to enhance community development, they have been promoted to set up a community radio to many areas of India since it is proved to be the most user friendly and economical and reached easily among the community people. This has to accomplish the impart between clique people and the community radio.

According to this policy, local community media should be promoted in order to enhance community development, at least at grass root level. Among various existing genres of local community media, Community Radio will prove most effective as it can easily cover a wider range of area as well as diversified audience. Besides, experiments with community radio in many parts of India have proved it to be the cheapest and the strongest medium for fulfilling communication gap between the community and the Govt. Community Radio has been proved to state ie explodes the "Right to Freedom of Speech and Expression"

\section{DISCUSSION}

From this research we have to discuss about the Shyamalavaani community radio in madurai which intensify the Women's participation and also the pogramme production

regarding well-being,cleanliness,lieracy,hygiene,dietary patterns and household management etc which steer a women to move from diversify lives to the new one.The important feature in the community radio is to upgrade a women to become more passion and focus towards work especially by the women listeners.

This Community Radio proved that the listeners for this community radio is mostly women.By using this Community radio frequently, it developed their prevalent facts and enhanced them to motivate their interest on someother issues such as literacy, sanitary,hygiene etc. They also wanted to get over the women from communal problems, legislative and remunerative in its area. In order to legalitize the politics, they wanted to know about the village panchayat system. The community radio serves to give the knowledge about the vote in generale elctions. To replace the panchayat systems to enhance vote in general elections. In policies of legislative developement, the panchayat representatives get a knowledge about castng votes in general elections. In policies of lucrative development, the community Radio helps women to get the jobs and also about the jobs update consequently to manipulate their income. Most importantly, community radio gives a voice for women community against gender discriminalities. In Shyamalavaani community radio stations women from rural community themself produce and participate in their programmes especially for agriculture such as they sell their own harvest fruits and vegetables from their agricultural land.

This will improve their organic food culture and also to get over from the home to focus more on work. Also, community radio given their opinions about women intellectual, efficient, parlimentive, civilazation, society, lifestyle development. Propensity and hankering on womens life has been bounce back to the women who is both producers and listeners on the Shyamalavaani community radio.

From the grassroots to the growing level, women has been developed towards their future potentiality. By using the concept of inerpersonal level between Shyamalavaani community radio station and women appears stronger connection regarding programmes and some challenges. Some of the challenges has been as followed by speaking in public without any fear, discriminating gender, confidence level in household management, and they able to collect vast range of information. They also improvised their writing skills and also about the cognition of using media like social , media and new media and become more familiar. Hence from this it can be proved that the radio has been the source for the development of women. And to enter the 
main subject regarding women such as the Shyamalavaani community radio gives a brave for women to fight for their moral, support, women literacy, malnutrition to nutrition and also about motherhood.

Radio also acts as a tutor for women about their legislative freedom to cast their votes in general elections inspite of panchayat.It delegates to brawl for their own community prosperity and also give braveness to speak their judgement regarding any kind of theme or concern.So the Wondering thing about the Community radio is if you used properly to get rid of any information it will boosten up for the empowerment of women.it gives confidence to the women in the particular community. By using ths radio rural people voices can reach over to government regading agriculture policies,education,laws and the access of different medium etc..From thiis discussion we have to conclude that the community radio serves as a temple for the rural people and it advise, address and charm.

\section{CONCLUSION}

In the contemporary world /society we need a lot of things especially for the women to manipulate and tackle their needs in the devoted society. The radio station acts as a channel in between the highly empowered society and the rural community people. To access important information rural community women used the community radio as a source to develop their focus.

In this regard, Shyamalavaani Community Radio gives reponse to the satisfaction of the people's needs and startegies. some of them are giving ears to the women what they are saying,by creating the literate community in addition to responding the women, by guiding the impartiality problems through community radio programmes. In addition to this the Shyamalavaani Community radio invite some experts/Resource persons to speak over the programmes to the rural community people for addressing the Women issues, current affairs and also they mainly concentrate only for women. When we start hear this community radio we have to get rid over from the rest of the world. This will submerge us to the radio. Now a days we need to get over this community radio to maintain the existing culture also. The radio is also taking part this need.

Empowerment in the name itself develops not only by community radio. They are voluntarily come forward to put forth their part time work to the local community women and also they offered teir reasonable wages directly .Begin with women, it gets consecutive over the lot of people for their employment. There was evidence of women empowerement through their involvement in the programmes and productions of the radio station. In the begining stage woment (girls) act as a pat time employed people and also a volunteer and social activist in some ways.

The Shyamalavaani community radio was exclusively open for thr programmes and productions and also the women suggest some ideas what they need to focus and concentrate more for particular community people.Women with various specializations are invited as Cheif guest and also they travel over for the entire rural community village to show over their agricultural lands and organic foods for the healthy life.Women also getting more confidence and also they will be the example for other women to tackle all the issues sucha as dowry,insanitation, unhygiene foods which affect them.The main usage of community radio is to educate the maths to completely uneducated people which has been handled over in vegetable shop,milkman etc.

Normally, women handling various issues daily in their daily day to day life.After the arrival of Shyamalavaani Community Radio in particular village women are actively participating and encouraging their happier life despite of they faced challenges.It hides away their pain and tears.From this the community radio stations give empowerment to women and also amuse oneself a consort position in Women Empowerment.

\section{REFERENCES}

1. Fraser, C. and Restrapo E. S. Community Radio Handbook.New Delhi: UNESCO, 2001.

2. Cammaerts, Bart. Community radio in the West: a legacy of struggle for survival in a state and capitalist controlled media environment. International communication gazette, 71.8. pp. 635-654. 2009.

3. Christooher,Media at the Margins: Policy and Practice in American, Canadian, and British Community Television,International Journal of Communication.2012.

4. Cammaerts, Bart. Community radio in the West: a legacy of struggle for survival in a state and capitalist controlled media environment International communication gazette, 71 (8). pp. 635-654. 2009.

5. Fraser, C. and Restrapo E. S.Community Radio Handbook .New Delhi: UNESCO, 2001.

\section{AUTHOR PROFILE}

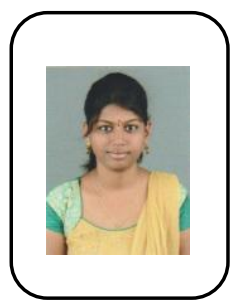

K. Abirami received B. Sc and M. Sc in Visual Comminication from Madurai Kamaraj University, Tamil Nadu. She is working as an assistant professor in the department of Visual Communication at Kalsaslingam Academy of Research and Education, Krishnankoil, Tamil Nadu since 2017. Her current research interests include women empowerment through community radio and film analysis. 